\title{
What is a Digital Weapon? Towards a Functional Approach to Hypermodern Warfare Media
}

\author{
Alessandro De Cesaris \\ Collège des Bernardins, Paris, France
}

\begin{abstract}
There is a wide debate concerning cyberwar and the new dangers of the Internet, but this debate focuses too often on practical issues, while the conceptual and somehow strictly "philosophical" dimension remains unquestioned. In this article, I will try to show that a better understanding of what we mean when we speak about weapons, or at least a better understanding of the new difficulties entailed by digital technologies in the field of military devices, can help us to provide a better analysis of the risks and of the ethical issues connected to contemporary fighting. In particular, I will argue that the so-called "digital turn" entails a blurring of the distinction between weapons and nonweapons, because in what I will call our "bypermodern era" the criteria we traditionally used in order to make this distinction have become obsolete.
\end{abstract}

\section{Keywords}

Conflict; Digital; Hypermodernity; War; Weapon.

DOI: 10.22618/TP.PJCV.20215.1.139003

The PJCV Journal is published by Trivent Publishing

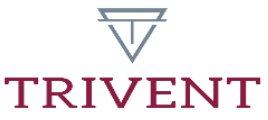

This is an Open Access article distributed in accordance with the Creative Commons Attribution Non Commercial (CC$B Y-N C-N D$ 4.0) license, which permits others to copy or share the article, provided original work is properly cited and that this is not done for commercial purposes. Users may not remix, transform, or build upon the material and may not distribute the modified material (bttp:/ / creativecommons.org/ licenses/by-nc/4.0/) 


\title{
What is a Digital Weapon? Towards a Functional Approach to Hypermodern Warfare Media
}

\author{
Alessandro De Cesaris \\ Collège des Bernardins, Paris, France
}

\begin{abstract}
There is a wide debate concerning cyberwar and the new dangers of the Internet, but this debate focuses too often on practical issues, while the conceptual and somehow strictly "philosophical" dimension remains unquestioned. In this article, I will try to show that a better understanding of what we mean when we speak about weapons, or at least a better understanding of the new difficulties entailed by digital technologies in the field of military devices, can help us to provide a better analysis of the risks and of the ethical issues connected to contemporary fighting. In particular, I will argue that the so-called "digital turn" entails a blurring of the distinction between weapons and nonweapons, because in what I will call our "bypermodern era" the criteria we traditionally used in order to make this distinction have become obsolete.
\end{abstract}

\section{Keywords}

Conflict; Digital; Hypermodernity; War; Weapon.

\section{Introduction: What is a weapon?}

The aim of this paper is not to define the notion of "digital weapon" as another sub-category among many others, in order to be able to discuss its specificity and maybe provide some insights about the ethical and legal consequences of the production, distribution and employment of new devices. What I am going to try is rather to provide an answer to the following question: how does the so-called "digital turn" — what Luciano Floridi called the Information Revolution ${ }^{1}$ — change our understanding of what a weapon is? Can we keep going with our customary notion of weapon, or are there other difficulties and problems forcing us to provide a new and deeper analysis?

The question concerning the status of weapons, their definition and description, is one of the key topics of the philosophy of war. Nevertheless, there is a certain tendency to take the notion of "weapon" for granted, to consider our common-sensical understanding of what a weapon is as sufficient in order to discuss what matters most for the political and social debate - mostly ethical and legal issues related to the usage of some devices. A look at the latest edition of the Dictionary of Military Terms, published by the Department of Defense of the United States, ${ }^{2}$ shows that among the many notions described, that of "weapon" is curiously

\footnotetext{
${ }^{1}$ Luciano Floridi, Information: A Very Short Introduction (Oxford: Oxford University Press, 2010).

2 Department of Defense, Dictionary of Military and Associated Terms (DOD, 2010).
} 
missing. ${ }^{3}$ There are, of course, many sub-categories of this notion: there is a definition of what a non-lethal weapon is, or of weapons of mass destruction. However, the Department of Defense probably regards as unnecessary to provide a general definition of what counts as a weapon.

These sub-categories are of course particularly relevant, since they require or imply special regulations or need the solution of specific issues from the legal or ethical point of view. They are also quite interesting, since each of these actually helps to reject those empirical - and often unconscious - ideas of what a weapon is that are too wide, or too narrow. The notion of non-lethal weapons contradicts the idea that weapons are instruments to kill. ${ }^{4}$ The notion of non-kinetic weapons contradicts the basic intuition that weapons are based on physical impact. ${ }^{5}$ Most of the time, the definition of these sub-categories is taking the notion of "weapon" for granted, and includes it in the definition. In fact, the vast variety of typologies of weapons shows us that it is extremely difficult to imagine a broad, general definition of weaponry. Yet, this definition is at the core of our notions of "conflict" and "war."

One of the issues concerning a viable definition of "weapon" is that it, just like the notion of "war," is historical. What we mean when we speak about weapons, or about war, considerably changed throughout the history of our civilisation, without mentioning the intercultural dimension. Another issue is that the notion of weapon seems to be strictly codependant with those of "war", "conflict" or "fighting." That leads us to two different possible approaches to the definition of weapon.

\section{A. Device-Based Definition}

The first approach is somehow the stronger one, and it could be regarded as a form of essentialism. According to it, it is the inherent structure of an object - the way it is built - that makes it a weapon. A sword, a rifle, a bomb, are weapons because they are made in such and such way. They possess an inherent power to harm and destroy, and they can be used in order to overcome an enemy.

This approach is at the core of the distinction between conventional and unconventional weapons. It is possible to use a random object in a fight, but a proper weapon is something different, because it is designed for fights: its affordance allows no mistake, ${ }^{6}$ even where we must distinguish between a kitchen knife and a military knife, or between a ceremonial sword and a proper sword. ${ }^{7}$

\footnotetext{
${ }^{3}$ This has already been noticed by Thomas Rid and Peter McBurney, "Cyber-Weapons," Rusi Journal 157/1 (2012): 6-13.

${ }^{4}$ David A. Koplow, Non-Lethal Weapons. The Law and Policy of Revolutionary Technologies for the Military and Law Enforcement (Cambridge: Cambridge University Press, 2006).

5 Stuart Casey-Maslen, Non-kinetic-energy weapons termed "non-lethal". A preliminary assessment under International Humanitarian Law and International Human Rights Law (Geneva: Geneva Academy of International Humanitarian Law and Human Rights, 2010).

${ }^{6}$ See James Jerome Gibson, The ecological approach to visual perception (Boston, MA: Houghton Mifflin, 1979) ; Donald A Normann, The Psychology of Everyday Things (New York: Basic Books, 1988).

7 John Forge's work is the main reference for this kind of approach. According to Forge, "harm" is the category we should look at in order to define what a weapon is. Without direct reference to his position, I will discuss some issues that emerge with this view. Anyway, a very important aspect of Forge's research is the extensive reference to design as a pivotal element in the analysis of modern weaponry. This is a huge aspect, that I will not have the space to discuss here. See John Forge, Designed to kill: The case against weapon research (New York/London: Springer, 2013); The morality of weapons research. Why it is wrong to design weapons (New York/London: Springer, 2019).

The same approach is followed by Rid and McBurney, "Cyber-Weapons."
} 
Yet, this approach has three limits. The first one is that the very possibility to speak of "improper weapons" proves that the domain of weapons somehow exceeds that of devices we expressly design for fighting. The possibility to speak of "proper" weapons is based on an essentialistic approach, but the possibility to speak of "improper weapons" somehow leads to a context-dependant definition.

Secondly, there is the classical issue of strong and essentialist philosophical approaches: is there a definition sufficiently narrow and precise to identify accurately what counts as a weapon? We have already seen that lethality cannot count as a criterion. Maybe the ability to inflict pain? Then how to account for those weapons that do not inflict pain (some kind of venoms or of chemical weapons, for instance) ${ }^{8}$ or those devices designed to inflict pain outside of a conflict? If one uses a whip in a BDSM session, is it correct to consider him armed? Another distinctive element could be the ability to neutralize. ${ }^{9}$ Yet, there is the same problem: are then anaesthetics or drugs weapons? As often happens with essentialistic approaches, the "essence" of weapons seems always to be too narrow or too extended. Some philosophers even argued that the idea of weapons as "means to an end" has become questionable. ${ }^{10}$

The third limit is that this approach strongly focuses on devices. We are accustomed to consider weapons as special kind of things, of identifiable individual objects. Yet, the history of the development of weapons has progressively made this assumption questionable. As I will argue, the first reason for it is that weapons have become integrated more and more in a technological system, and are thus hardly distinguishable from their associated milieu. ${ }^{11}$ More generally, though, the device-based approach is limited because it does not take into account the relationship between the device, its components and the infrastructure that makes it functioning possible.

\section{B. Context-Based Definition}

The second approach is quite anti-essentialistic, and can be considered as the weak one. According to it, there is no strict definition of what a weapon is outside of the context of a conflict. In other words, weapons are the instruments of conflict, be it individual of collective, a fight or a war. This approach seems implicit in the (very brief) philosophical investigation made by post-phenomenology about the nature of weapons. ${ }^{12}$ The post-phenomenological point of view argues that a gun has no inherent nature, but is properly a weapon only when wielded by a man, and its nature changes according to the context of its use. Subject and technological device "influence" each other, they are an integrated system that we must consider in its entirety in order to provide a useful analysis of weapons.

\footnotetext{
8 V.P. Gulin, “A New Conception of War,” Military Thought. A Russian Journal of Military Theory and Strategy 1 (1997): 20.

9 Please note: Not "to neutralize the enemy," because that would already be a context-dependant definition.

10 See Günther Anders, Die Antiquiertheit des Menschen. Über die Seele im Zeitalter der zweiten industriellen Revolution (München: Beck Verlag, 1961), 247-263 ; Stephen P. Lee, "Weapon of Mass Destruction. Are they morally special?," in War. Essays in Political Philosophy, ed. May Larry (Cambridge: Cambridge University Press, 2008).

11 Gilbert Simondon, Du mode d'existence des objets techniques (Paris: Aubier, 1989).

12 Bruno Latour, Pandora's Hope. Essays on the Reality of Science Studies (Cambridge, MA: Harvard University Press, 1999) ; Soren Riis, "The Symmetry between Bruno Latour and Martin Heidegger: The Technique of Turning a Police Officer into a Speed Bump," Social Studies of Science 38, no. 2 (2008): 285-301.
} 
When Clausewitz, in his classic essay $O n W$ ar, states that fighting and weapons influence each other, ${ }^{13}$ he is expressing a similar position. ${ }^{14}$ According to Clausewitz, weapons are the devices of war, ${ }^{15}$ one could say "the media of conflict," and therefore their definition is strictly context-based.

The limit of this approach, of course, is that it is rather nominalist, and completely avoids the question instead of answering it. A purely context-based definition of weapons does not even allow a distinction between conventional and unconventional weapon, and entails some risk of circularity: we could end up defining conflict based on the use of weapons, and weapons based on their usage in a conflict. At the same time, Clausewitz himself shows that weapons are just one sub-category of the kind of devices used in a conflict: not all instruments and objects deployed in a war - armours, communication devices, means of transport and so on - are weapons.

I will argue that while both approaches are fit in order to describe some aspects of the latest developments in weaponry, the notion of "digital weapon" entails conceptual issues that cannot be solved through either. There is a wide debate concerning cyberwar and the new dangers of the Internet, but this debate focuses too often on practical issues, while the conceptual and somehow strictly "philosophical" dimension remains unquestioned. I will try to show that a better understanding of what we mean when we speak about weapons, or at least a better understanding of the new difficulties entailed by digital technologies in the field of military devices, can help us to provide a better analysis of the risks and of the ethical issues connected to contemporary fighting. In particular, I will argue that the so-called "digital turn" entails a blurring of the distinction between weapons and non-weapons, because in what I will call our "hypermodern era" the criteria we traditionally used in order to make this distinction have become obsolete. For this reason, in this paper I will not offer a "taxonomy" of weapons, in which a subset covers the domain of digital ones: in fact, my main argument is that what we could call "digital weapon" today is in principle indistinguishable from the digital media we use in our everyday and professional life. This means, above all, that we will need a third approach — other than the device- and the context-based — to discuss the issue. In particular, I will propose a functional approach to the question of weaponry: according to this position, the term "weapon" does not describe a device or a contextual property of an object, but rather a function - a certain kind of operation.

My analysis will proceed as follows: in the first part, I will briefly recall some aspects of modern warfare that made the definition of weapon somehow unproblematic. In the second part, I will sketch an outline of what I call "hypermodernity" and in doing so I will highlight those aspects that make our understanding of what a weapon is problematic. Finally, I will try to suggest some key elements of "hypermodern warfare" and to show what conceptual issues are introduced by the introduction of digital technologies in the domain of weaponry. Before proceeding further, I would like to point out that the clear distinction between "modern" and "hypermodern" warfare is methodological, but that it does not imply that there has been -

${ }^{13}$ Carl Clausewitz, On War, trans. Michael Howard and Peter Paret (Oxford: Oxford University Press, 2007), 104.

${ }^{14}$ Nevertheless, according to Clausewitz fighting does not require the use of weapons. It is very interesting to see how ambivalent Clausewitz is when he considers weapons. They are not necessary in order to describe fighting from a "theoretical" standpoint, but at the same time, their use is so determinant that many aspects of his theory of war explicitly use the notion of weapon. It has also been shown that there is a common tendency to identify war with the use of weapons, or at least to consider weapons as an essential part of war. See Kathleen Malley-Morrison et al. (eds.), International Handbook of War, Torture and Terrorism (New York: Springer, 2013).

${ }^{15}$ Clausewitz, On War, 104. 
or will be - a clean "passage" from a certain way to organise conflicts to another. On the contrary, our era is structurally identified by the intertwine of modern and hypermodern elements: the theoretical framework I am going to offer is simply designed to clarify some trends and highlight some new issues, which are impossible to solve according to a purely modern understanding of weaponry and conflict.

\section{The Comfort of Borders. Modernity and Warfare}

In 1651, Thomas Hobbes published his Leviathan, one of the most important works of political theory in the modern era, and possibly the most intense description of the foundations of modern state. The frontispiece of the book is iconic, as almost as famous as the work itself: The Leviathan, in the shape of a man made of men, holds the symbols of secular and spiritual power - a sword and a crosier — as he stares at the reader. Under him two sets of pictures appear, at the left and at the right of the title. On the left side are elements pertaining to the secular domain: a castle, a crown, a cannon, some rifles and flags, and finally a depiction of a battle. On the right side, we can find the spiritual and religious elements that are analogous to the firsts: a church, a mitre, the "thunderbolts of excommunication," the conceptual distinctions of scholastic thought and, finally, a council.

I am not going to attempt a general analysis of the frontispiece, which by the way has already been offered by many scholars in the field of political theory and history of art. ${ }^{16} \mathrm{I}$ am mentioning this iconic page of our cultural history because it somehow summarizes what we could call the "modern conception of weaponry," showing its evidence but at the same time highlighting its grey areas.

Swords and cannons are clearly weapons. They are media of secular power, and they are instruments we use in order to enhance our power and our ability to overcome the enemy in a fight. A device-based approach seems to be perfectly fit in order to describe these technical objects as weapons. Yet, already at this level, we see that it is not a purely device-based approach that presents us these devices as weapons. Cannons, rifles and swords are already put in the context of secular power; they are already defined thanks to a political and conceptual distinction. The conceptual issues I have highlighted in the case of a device-based approach are not present here, because the way modernity understands weapons is already an interaction between a device-based and a context-based approach. Most importantly, here a spatial distinction is clearly at work: there are borders that clearly help shaping our implicit understanding of what a weapon is.

War is not just a spiritual or political condition: it has its own spaces — the battlefield, the border zone. Modern warfare rests on the idea that the subjects of war are states, political entities provided with specific spatial borders. A cannon is clearly a weapon, but it is identified as such also because it has a clear function: artillery is the medium external conflict, the kind of violent device a state uses in order to defend its borders or to attack those of the enemy. In the same way, rifles and swords are weapons that the State also uses to maintain its internal peace; they are media of internal as well as of external conflict. Max Weber's definition of the State, as the entity that holds the monopoly of the legitimate use of physical force, ${ }^{17}$ entails

\footnotetext{
16 See Horst Bredekamp, Thomas Hobbes. Der Leviathan. Das Urbild des modernen Staates und seine Gegenbilder: 1651-2001 (Berlin: Akademie Verlag, 2012); Carlo Ginzburg, Paura reverenza terrore. Cinque saggi di iconografia politica (Milano: Adelphi, 2015).

17 Max Weber, The Vocation Lectures. Science as a Vocation. Politics as a Vocation, trans. Rodney Livingstone (Cambridge, MA: Hackett Publishing, 2004), 33.
} 
the need to define the media of this use, both external and internal. ${ }^{18}$ Weapons can be defined as the means through which a State exerts its physical force, both against an enemy State and within its own borders.

As Carl Schmitt remarks, the analogy between the two sets of pictures in the frontispiece of the Leviathan suggests that excommunication and dialectical distinctions also are weapons. ${ }^{19}$ It is rather interesting, since it allows a metaphorical extension of the distinction between "internal" and "external" weapons I have just suggested. What is excommunication, if not the way the Church has threatened and attacked secular power throughout history? What are syllogisms and doctrines, if not the means the Church has used in order to overcome and discipline its internal enemies? In this analogy, what is missing is only the term "physical." Just like secular weapons are means for the expression of physical force, "spiritual weapons" are the means for the expression of symbolic force - which makes them weapons only in a metaphorical way. One could say that "spiritual weapons" maintain the contextual aspects of the definition of modern weaponry, but lose the device-based ones.

I have said that in the case of modern weaponry an interaction between a device-based and a context-based approach is already at work. This statement needs further clarification: in fact, this does not mean that in the case of modern weaponry we need to look at the context in order to understand what a weapon is. This would be counterfactual: one of the key aspects of modern weaponry is precisely that weapons are immediately recognizable. Cannons, pistols, swords, bombs, do not offer us any kind of conceptual issue. A purely context-based approach only serves as a "negative limit" for the notion of weapon, namely, to avoid an overextension of the notion of "weapon": while it is clear why some devices are weapons, it is not as clear why some other devices are not. ${ }^{20}$ Again, here the aim is to keep faith to our common sense, and to our intuitive understanding of what weapons are.

What I mean, when I state that in the case of modern weaponry a context-based approach is already at work, is that modern weapons are objects that are produced in order to "concretize" contextual elements. Here I use the word "concretize" as Gilbert Simondon understood it in his works: modern weapons are specific kinds of technical objects, whose shape and function already internalizes not only technical practices and needs, but also social and political structures. ${ }^{21}$ The device-based approach seems to work perfectly in the case of modern weapons, because modern weapons are essentially devices, and their contextual dimension is already embedded in their modes of production.

Now, I need to clarify what I mean when I speak of "context." When I proposed a context-based approach to the definition of weapons, "context" was a space much more symbolic than real; it referred to the complex system of ends, situations and practices surrounding the way we produce and use a certain kind of objects. However, in the case of modern weaponry, the word "context" also gains a very concrete nuance. There are "spaces" for the use of weapons — shooting ranges, sport competitions, battlefields and military checkpoints. There are also well-defined spaces of production and of sale for weapons: arms

18 Aside from the consideration that here we only consider physical force on humans, there are two exceptions to this general definition, which I am not going to consider in this paper for the sake of shortness: sports, and self-defence.

${ }^{19}$ Carl Schmitt, The Leviathan in the State Theory of Thomas Hobbes. Meaning and Failure of a Political Symbol, trans. George Schwab and Erna Hilfstein (London: Greenwood Press, 1996), 18.

${ }^{20}$ For instance, it is hard to clarify why a whip is not a weapon according to a device-based approach. Whips are instruments used as media of physical force, they aim at harming, and they serve as a mean to submit someone's will to our own. The only reason not to account whips as weapons is to show that the context of their use is not compatible with the definition of weapon.

${ }^{21}$ See Gilbert Simondon, Du mode d'existence des objets techniques; Sur la technique (1953-1983) (Paris: PUF, 2014). 
factories, armouries and other spaces for the production and exchange of weapons are clearly defined, and their functioning is strictly regulated by laws (as the Arms Trade Treaty). The production and commerce of weapons are clearly differentiated - at least on paper - from all other kinds of production and commerce. ${ }^{22}$ Modernity is the age in which the production of weapons is linked to the existence of distinct professions (the gunsmith, the armorer and so on - Beretta, one of the oldest weapon producers still active today, was founded in 1526)..$^{23}$

More generally, modernity is an age of separation. The notion of "border" is symbolically determinant for all his aspects: there are borders between states, but also between sectors of the public space, professions, and people. Another important aspect of modern weaponry is that it creates new forms of social identity: the soldier, the police officer, the criminal, are new social roles based on the use of weapons. Again, the relationship between weaponry and subjectivity is an interactive one: weapons already concretize a certain kind of training, some social and logistic needs. At the same time, the use of a certain kind of weapon contributes to the definition of the fighter's identity: the soldier of the US Army uses the SIG Sauer P320; that particular gun is a material component of his social identity, as well as a part of his function. The production and distribution system we live in does not only identify our weapons according to their types, but also as individual objects: each weapon has a serial number, so that it is possible to identify it and its owner. There is an entire social system that structures the circulation of weapons in our age, an "associated milieu" 24 that provides not only the infrastructure we need to materially use our weapons, but also the social context that specifically regulates the way they work in our private and public spaces.

The modern way of dealing with the question of weaponry is to create specific institutions in order to assign to conflict its own "borders." 25 The institutionalization of conflict is the creation of spaces and times expressly devoted to combat, or the training of individuals expressly chosen to use these "media of physical force." This also requires the creation of specific laws, specific productive structures and social practices. It is also for this reason that the modern conception of weaponry seems to be unproblematic: the production of specific devices, showing unequivocally distinct features, that work within well-given spatial-temporal borders and are operated by a well-determined kind of individuals, is only possible in an age that makes of the differentiation of spaces, times, practices and roles its trademark.

This description follows, of course, the Weberian-Luhmannian framework, according to which modernity is the age of differentiation. ${ }^{26}$ For the sake of our topic, however, are of particular interest those accounts that recognize technology, if not as a direct cause, at least as a condition of possibility for the differentiation process typical of modernity. It is the case,

\footnotetext{
22 United Nations Institute for Disarmament Research (UNIDIR), Reporting on Conventional Arms Trade (2018). Available at https://unidir.org/sites/default/files/publication/pdfs/reporting-on-conventional -arms-trade-synthesis-handbook-en-699.pdf, Accessed February 11, 2020.

23 Alexander Moseley, for instance, grounds his distinction between different kinds of war on the production and use of technological devices and weapons. See Alexander Moseley, A Pbilosophy of War (New York: Algora Publishing, 2002).

${ }^{24}$ Gilbert Simondon, Du mode d'existence des objets techniques.

25 The importance of the notion of "border" for modern warfare becomes evident when contrasted with cyberwar, namely with a kind of war in which our traditional notion of border loses its meaning (Huyghe 2011, 22-24).

${ }^{26}$ See Niklas Luhmann, "Differentiation of Society," Canadian Journal of Sociology 2, no. 1 (1977): 29-53; Jeffrey C. Alexander, "Durkheim's Problem and Differentiation Theory Today," in Social Change and Modernity, ed. Hans Haferkamp and Neil J. Smelser (Berkeley: University of California Press, 1992), 179205 ; Klaus Eder, "Contradictions and Social Evolution: A Theory of the Social Evolution of Modernity," in ibid., 320-350.
} 
for instance, of McLuhan's media theory: according to McLuhan modern rationality is a consequence of press, and differentiation is the expression of a "typographic" culture. ${ }^{27}$

In this way, it is possible to understand how a technological revolution influences human rationality and culture to the point of generating an epochal shift. As I remarked at the beginning of this essay, the problem is not just to provide a description for a certain new kind of weapons, whose functioning is based on digital technologies. I tried to show that the modern understanding of weaponry is deeply embedded in a modern cultural paradigm, based on the notions of differentiation and border. If the so-called "digital turn" has generated an epochal shift, which is not only technological but rather invests human life and rationality as a whole, then this modern frame is no longer viable for our new cultural condition, that I call "hypermodern." 28 There are thus two questions: the first is how the shift from modernity to hypermodernity makes our understanding of weaponry and of warfare obsolete; the second is how to create a new conceptual frame, in order to provide a hypermodern conception of weaponry and of warfare.

\section{The Implosion of Space. From Modernity to Hypermodernity}

It is possible to present the history of modernity - and of modern warfare — through the spatial evolutions made possible by technology. In his brilliant reconstruction of World history, Carl Schmitt notably argues that the history of civilization is the history of a struggle between land and sea powers. ${ }^{29}$ At the same time, however, Schmitt recognizes two groundbreaking events in the evolution of this fight: the first is the progress of sea traveling, a progress that generated the need for more and more regulations. The possess and the status of sovereignty in the open sea became a problem precisely when technology and sailing techniques made it possible to move on water just as easily as on land. ${ }^{30}$ For the first time it was possible to see and map the Earth as a whole, and to set precise borders across the seas and the oceans between States..$^{31}$ Therefore, starting from the $16^{\text {th }}$ Century political theory is more and more interested to conceptualize sea power, and to extend the precision of borders to the domain of water. ${ }^{32}$ In this way, it is possible to understand early modernity as a cartographical operation, an operation that involves the evolution of power as its consequence and of technology as its condition of possibility.

The second event is the "conquest of the third element," 33 namely the invention of the airplane. The peak of modern warfare is the close interaction between these three elements - land, sea and air — as Christopher Nolan's movie Dunkirk shows with incredible

${ }^{27}$ See Marshall McLuhan, The Gutenberg Galaxy (Toronto: University of Toronto Press, 2011); Kenneth E. Boulding, "Il est assez typique des esprits très créateurs d'enfoncer de très gros clous mais de taper toujours un peu à côté," in Pour ou contre McLuhan, ed. Gerald Emanuel Stern (Paris: Seuil, 1969), 61-69. ${ }^{28}$ Many scholars, in different fields, have used the notion of "hypermodernity", often with very different meanings. In this essay, I will not assume any specific position towards the concept, as I prefer to focus the attention on the specific topic of weapons. I will also not discuss the other words used to describe our age - post-postmodernity, sur-modernity, ultramodernity, late modernity and so on. Of course, the analysis of what I call "hypermodern warfare" can count as a case study for a general theory of hypermodernity. At the same time, some hypotheses concerning the features of hypermodernity - some of which I will highlight in chapter 3 - are at the basis of my analysis of digital warfare.

${ }^{29}$ Carl Schmitt, Land and Sea, trans. Simona Draghici (Washington, DC: Plutarch Press, 1997).

${ }^{30} \mathrm{Ibid}$.

${ }^{31}$ Franco Farinelli, La crisi della ragione cartografica (Torino: Einaudi, 2009).

32 Ernesto Calogero Sferrazza Papa, Modernità infinita. Saggio sul rapporto tra spazio e potere (Milano-Udine: Mimesis, 2019).

${ }_{33}$ Carl Schmitt, Land and Sea, 57. 
expressive power. Adding a new element to the formula, the problem of flying set a new challenge for the modern political order. Modernity met this challenge in its own way, extending the notion of "border" to the sky, a solution that is perfectly viable in the case of well-defined objects such as airplanes. For this reason, while the conquest of air made modernity somehow "more complex," it did not disrupt the modern order to the point of forcing it to question its own principles.

This so-called "second world-wide spatial revolution" 34 cannot be limited to airplanes. The invention of transmitters, of the radio, of rockets and satellites, these are also essential features in the shift from a two-dimensional — cartographical — worldview to a completely different mindset, that for the first time had to consider the Earth as a globe. ${ }^{35}$ However, the new availability of means of transport able to cross the sky at incredible speed also changed forever the nature of warfare. The use of nuclear weapons is only possible thanks to the new technologies of distance, namely to the ability to drop a bomb and fly away fast enough, or to launch a missile able to cross entire regions before hitting its target. With the new speed reached in the sky, for the first time modern war lost its structural link to a "space," the battlefield. At the same time, as Günther Anders already made clear in his work, some kind of weapons - nuclear ones above all — completely overcome any sort of boundary, be it spatial or social, or even temporal.

Another key element of this technological shift is that the device-based approach to the understanding of weapons started to show new limits. The reason for this is that weapons became more and more dependent on their delivery systems, as on the technological instruments used to identify and reach their target or calculate their route. Late modern weaponry requires huge technological infrastructures, systems that are not per se weapons but that are essential to the correct functioning of weapons themselves. The idea that a weapon is a delimited, individual object shaped in a certain manner starts to lose its grasp on the reality of warfare. ${ }^{36}$ At the same time, the so-called military industry becomes something much wider than arms industry: rockets, missiles and airplanes are produced to invade other countries and to improve communication or to explore. The border between the production chain of weapons and other productive structures starts to blur.

At the same time, the very notion of "border" became weaker and weaker. In a world that became more and more connected, with radio signals crossing the air each moment in all directions, the image of the state as a well-limited organic entity ${ }^{37}$ started to lose its meaning. This process goes along with the emergence of new political entities, agencies or corporations that are in control of an infrastructure expanding beyond the borders of political states. As the so-called "Westphalian order" starts to collapse, 38 our very understanding of conflict has to adapt to this new scenario. In a way, the emergence of international terrorism is only a

34 Matteo Vegetti, L'invenzione del globo. Spazio, potere, comunicazione nell'epoca dell'aria (Torino: Einaudi, 2017).

35 Franco Farinelli, La crisi della ragione cartografica.

36 Quite interestingly, for instance, the definition of "chemical weapon" on the website of the Arms Control Association distinguishes the proper weapon - the toxic agent - from its delivery system (https://www.armscontrol.org/factsheets/Chemical-Weapons-Frequently-Asked-Questions\#I). At the same time, though, this very delivery system allows us to distinguish a military use of that particular chemical product from another kind of use - an industrial one, for instance.

${ }_{7}$ See Peter Sloterdijk, Im selben Boot. Über die Hyperpolitik (Frankfurt am Main: Suhrkamp Verlag, 1994) ; Sphären II. Makerosphärologie. Globen (Frankfurt am Main: Suhrkamp Verlag, 1999).

38 Andrew Linklater, The Transformation of the Political Community. Ethical Foundation of the Post-Westphalian Era (Hoboken: Wiley, 2011); Luciano Floridi, The Fourth Revolution. How the Infosphere is reshaping human reality (Oxford: Oxford University Press, 2014), 175. 
consequence of a new political — and therefore spatial — configuration, in which borders are not what they were before, since each spatial entity is structurally porous. ${ }^{39}$

Now, it is possible to argue that with the so-called digital turn a fourth spatial revolution took place, in a different sense than the one proposed by Luciano Floridi. ${ }^{40}$ Keeping in mind Marshall McLuhan's understanding of the evolution of technology and society, it can be presented as the conquest of another element: after water and air, we finally mastered electricity. According to McLuhan, this elemental shift causes a passage from the explosive trend of modernity to a new, implosive paradigm. There is no more expansion, but concentration; no more differentiation, but melting together of all elements; no more succession, but simultaneity. "The great principle of classical physics and economics and political science, namely that of the divisibility of each process, has reversed itself by sheer extension into the unified field theory." 41 While the elemental juxtaposition of modernity, that tried to organize space by differentiating and assigning a function to each element, resembles the composition of the human body, the new electrical system acts like the central nervous system, in which all is one.

McLuhan is already expressly writing about the Age of information, namely about the digital turn. His intuition is very similar to Luciano Floridi's notion of "hyperhistory": according to Floridi, the Age of information is an era in which all domains of human life become dependent on one specific kind of technology, namely Information and Communication Technologies (ICTs). ${ }^{42}$ Just like in McLuhan's vivid account of our new society, Floridi's notion of hyperhistory describes a situation in which the old distinctions proper of modernity lose their significance. In turn, this account of the technological evolution of Western societies is perfectly compatible with Gilbert Simondon's reconstruction of technological progress. According to Simondon, the progressive concretization of the individual technical object requires an associated milieu that is more and more complex, to the point that the technological milieu is more essential than the object itself. ${ }^{43}$ This is precisely what Floridi describes in the case of ICTs: all aspects of our life, from industrial production to social relations, from politics to art and entertainment, from health to finance, are made possible — and are structurally shaped — by ICTs. As I briefly remarked earlier, this is also the case for warfare.

What does hypermodern warfare look like, then? Before pointing our attention to the specific area of "digital weapons," let us go back to those features that made the modern understanding of weaponry somehow unproblematic. I argued that modernity solved the problem concerning the definition of what a weapon is through three operations, thanks to which it embedded some contextual features of weapons in their design as devices. The first (a) was the definition of a specific space-time for conflict. The second (b) was the institutionalized differentiation of production and commerce of weapons. Finally (c) there was the creation of specific social roles - or, more deeply, of specific "modes of subjectivation" - for those who use weapons.

Now, describing the so-called digital turn as a paradigm shift, and therefore as an "implosion of modernity," means showing why these operations are no longer possible in the new digital context. Concerning (a), I have already remarked that the conquest of air somehow made the definition of an appropriate space-time for conflict problematic. This,

\footnotetext{
${ }^{39}$ François-Bernard Huyghe, "Cyberwar and its Borders," in Cyberwar and Information Warfare, ed. Daniel Ventre (Hoboken: Wiley, 2011), 1-30.

${ }^{40}$ Luciano Floridi, The Fourth Revolution. How the Infosphere is reshaping buman reality.

${ }^{41}$ Marshall McLuhan, Understanding Media. The Extensions of Man (Boston, MA: MIT Press, 1995), 35.

${ }^{42}$ Luciano Floridi, The Fourth Revolution. How the Infosphere is reshaping human reality, 1-24.

${ }^{43}$ Gilbert Simondon, Sur la technique, 269-278.
} 
however, is much truer in a context in which distances are not just easily covered, but disappear as a factor. The "implosion of space" is a general overcoming of the problem of distance, where weapons are no longer bound to a specific space or time. In a world where everything is interconnected, ${ }^{44}$ war can be everywhere and anytime. If the sublation of space and time is the essential feature of digital technologies, the determination of spatial or temporal boundaries will be of no use for the definition of what a "digital weapon" is.

Concerning the point (b), already with aircraft and space industry the clear distinction between military and civil industry became problematic. The new landscape of industrial production is becoming more and more unified, with a few giants offering a wide variety of digital products. The distinction between military and civil use is no longer essential as before. As Floridi remarks, "iRobot produces both the Roomba 700 that vacuum-cleans your floor and the iRobot 710 Warrior that disposes of your enemies' explosives." 45 The progressive integration of productive systems under the guide of ICTs - the unification of the associated milien for all devices — blurs the difference between sectors.

Finally, the tendency to unify and integrate different productive systems and infrastructures under the control of Information Technologies also leads to the reshaping of traditional social roles. Computer scientists become more and more present in all fields, from economics to medicine, from production to commerce. This is a tendency not only on the professional level, but also on the social one: the difference between producers and consumers is constantly blurring, while the traditional forms of identification - the Citizen, the Believer, the member of a specific ethnic group - leave space to a new and much different figure, the User. In this scenario, there is no form of subjectivity exclusively and distinctly linked to the idea of a "digital weapon" - the closest thing to it, the Hacker, is not defined by the use of a specific kind of device, but by a set of skills and a kind of practice.

Of course, this shift is neither sudden nor absolute. Elements of modern warfare are still present and active today, and our reality still features soldiers, guns, missiles. The key element, here, is that modern warfare is much more complex today because of the introduction of digital technologies, and it is not alone: a new kind of warfare is now shaping our world politics. After this pars destruens, in which I tried to show why modern criteria are no longer viable to describe our new technological condition, it is finally possible to address the specific problem of digital weapons.

\section{Total Warfare. From Traditional Weapons to Information Technology.}

Hypermodern warfare is a complex system, in which modern elements are integrated with new military systems. The debate concerning the relationship between digital technologies and war often focuses on two aspects:

a. Digital technologies as logistic support for traditional warfare.

In this case, the analysis focuses on how digital technologies improve the communicational and logistic aspects of war. Thanks to digital technologies, it is easier to coordinate the troops, to locate the enemy, to organize movements and so on. This kind of analysis does not touch the specific problem of digital weapons, so it will not be taken under consideration.

b. Digital technologies as enhancements for traditional weapons.

More specifically, some analyses focus on how digital technologies improved already existing weapon systems. Digital pointing systems, digital bullet counters, "smart

\footnotetext{
44 Parag Khanna, Connectography. Mapping the Future of Global Civilisation (NY: Random House, 2016).

${ }^{45}$ Luciano Floridi, The Fourth Revolution. How the Infosphere is reshaping buman reality, 203.
} 
guns" are examples considered in this case. Here, again, digital technologies are a support for a device whose core is based on a pre-digital technology. If it could make sense to talk about "digital weapons" in this case, this kind of analysis still misses the core aspect of the technological revolution we are facing: the possibility to create a weapon that is no longer based on the traditional functioning of predigital technologies (kinetic impact, poisoning, burning).

There are, actually, some weapons that can count as "digital weapons" since they rely entirely on the possibilities opened by the digital turn. Drones are a good example. The automation of war introduced new problems in the theorization of warfare, which are often connected to the relationship between subject and instrument, or to the question of who is actually "fighting" in the conflict. ${ }^{46}$ Yet, I would like to argue that even in this case digital technologies are just a "delivery system" for a weapon that still works in a traditional way, by firing bullets or dropping bombs. I do not mean that the introduction of drones does not completely change the nature of traditional weapons. I am just arguing that in this case we are discussing a digital reconfiguration of pre-digital war technologies. While it is a very interesting topic, it still does not touch the core of what a digital weapon can be.

The category of "cyberwarfare" (or "cyberwar", or "information warfare") usually tries to consider more specifically how digital technologies can be directly involved in a new kind of conflict. It refers to a wide variety of phenomena, and in order to discuss the specific problem of the definition of digital weapon it will be necessary to make some clarity. As Daniel Ventre pointed out, the notion of "cyberwar" is structurally connected with the notion of "cyberspace". This is somehow a problematic concept ${ }^{47}$ since it puts together very different aspects of digital technology. One could say that cyberspace has three layers: the physical infrastructure (hardware) that supports applications and communication between terminals; the software infrastructure (or subface) that organizes the flux and the elaboration of data; finally, the dimension that is accessible to every user, the interface where people actually interact with the machine and among themselves. ${ }^{48}$ According to Ventre, cyberwar consists in those operations that can count as attacks to any of these dimensions. Destroying a server, hacking a mainframe, manipulating content on a social network are good examples of "information war." 49

While this position is understandable in the context of an analysis of cyberwar, it becomes problematic when it comes to the definition of a digital weapon. In fact, the destruction of hardware often requires the use of pre-digital weapons (bombs, firearms, even a club). Here digital technologies are the object, not the medium of the attack. On the third layer, on the contrary, digital technologies are the medium, but not the object of the attack. In the first case, we clearly have an example of traditional warfare, analogous to the sabotage of a bridge in order to cut of the enemy's supplies. In the second case, we have the digital version of other traditional aspects of conflicts, for instance propaganda and espionage. I would like to argue that the only proper kind of cyberattack takes place on the second layer: in this case, digital technologies are at the same time the medium and the object of the attack. In this

\footnotetext{
46 Grégoire Chamayou, A Theory of the Drone, trans. Janet Lloyd (New York: The New Press, 2015).

${ }^{47}$ See Julie E. Cohen, "Cyberspace and/as space," Columbia Law Review 107 (2007): 210-257; FrançoisBernard Huyghe, "Cyberwar and its Borders."

${ }^{48}$ It is important to remark that we are actually dealing with a "space" only in the case of the first and of the third layer. In the first case, in fact, we have a material infrastructure situated in space. In the third case, we have graphic user interfaces that give us a spatial representation of the code. When it comes to the second layer, we are dealing with a logical structure that is spatial only in a topological sense, since it determines a relation of dependence and of priority between logical elements.

${ }^{49}$ Daniel Ventre, Information Warfare (Hoboken: Wiley, 2016), 263.
} 
paper, as I already pointed out, when I speak of "digital weapons" I try to exclude any generic reference to digital technologies as a logistic support or as a technical enhancement. In this sense, the term "cyberwar" is far more comprehensive than the notion of digital weapon, even though, of course, the two concepts are closely related.

This is a big difference with respect to traditional, pre-digital weapons: we are accustomed to imagine a weapon as a device that has a direct effect on the physical world, on a living being or on another kind of objective. In the case of information technologies, the effect on people and other targets is always mediated by an effect on the very same digital infrastructure. Unlike pre-digital weapons, the notion of "digital weapon" requires then the distinction between the immediate object of the attack and the mediated target. This could be a first attempt at the definition of a digital weapon: it is a digital technology that, through the attack of another digital technology, is designed to harm, destroy or subjugate a living or lifeless target.

Yet, this definition is very problematic. What is in fact a "digital technology"? And how do we distinguish it from other digital technologies? Moreover, how do we determine whether that technology is "designed" for this function?

As I have already pointed out, context-dependant approaches lose their strength when it comes to the hypermodern era. We are not able to identify a technology as a digital weapon based on its production, or the kind of person that uses it, or the space and time in which it is used. We are also unable to use the notion of "war" in order to justify the identification of a technology as a weapon, since cyberattacks have been executed also - or even predominantly - in a situation of peace..$^{50}$ Therefore, the state of war is not determinant in order to identify something as an attack, as a weapon or as a hostile technology.

A device-based approach is also unsuccessful, and for two reasons. Firstly, it is impossible to distinguish between a digital device used as a weapon and a digital device used for other means. In the digital environment, the distinction between weapon and non-weapon completely vanishes, since every device can in principle used to conduct a cyber-attack - for instance, a Distributed Denial of Services attack. More importantly, it is the very notion of "device" that becomes somehow obsolete. The digital infrastructure is so complex that the distinction between a device — for instance a laptop — and the digital milieu that supports it has no meaning.

Someone hacks the defence system of a hospital, shuts down the life supporting system of one of the patients and kills him. Which one is the weapon here? The laptop he used to attack the system? The system itself? The infrastructure that made the connection between his terminal and the system possible? Such question does not make any sense. As our life become more and more dependent on devices and technological environments, digital attacks that harm us become more and more possible. The very same infrastructure that supports our life can harm it. It is not only that a device-based approach to digital weapons fails: it does not make any sense to imagine digital weapons as devices, and material individual "things."

Shall we say, then, that the very notion of weapon is obsolete? I believe not. We still have a need for the notion of "weapon" in the digital environment, since we still have the need to consider someone "armed and dangerous" when it comes to digital technologies. The case of the notorious hacker Kevin Mitnick is a very good example ${ }^{51}$ : the only reason to deny him the use of computers is precisely that those technologies, in his hands, become weapons, namely that when in possession of a computer Mitnick has to be considered armed.

\footnotetext{
${ }^{50}$ Daniel Ventre (ed.), Cyber Conflict. Competing National Perspectives (Hoboken: Wiley, 2012), xi.

51 Kevin D. Mitnick, William L. Simon, The Art of Deception. Controlling the Human Element of Security (Hoboken: Wiley, 2003).
} 
Since it is impossible to use either a device-based or a context-based definition of digital weapon, I would like to propose a functional definition of it. A digital weapon is such not because it is an object shaped in a certain fashion, but rather because it expresses a certain kind of function - be it a practice, the operation of a device or something else. I would like to identify this function as "attack." As we saw, Ventre's definition of cyberwar extensively uses the notion of "attack." While I have already underlined some issues in his theory, I believe that this notion is effective when it comes to describing weaponry. Weapons are those media - devices, skills, practices — designed to operate a certain function: attack. Some remarks on this point:

a. The notion of "attack" is not context-dependant. On the contrary, it is the notion of "attack" that often allows to recognize the context of an action. There is a war because someone is attacking, and not all the way around.

b. The use of the notion of "attack" avoids any reference to categories such as "harm," "violence," "killing" and so on.

c. The switch from a device-based to a functional approach to weaponry allows to recognize certain skills and competences as "weapons." This is very important, because it shows that a new kind of social differentiation is taking place: throughout modernity there were "professional figures" of weapon users: soldiers, policemen, in a way policemen and terrorists. In the hypermodern era this form of differentiation implodes.

d. The use of the notion of "attack" allows to develop an expanded theory of weaponry, that also recognizes more abstract, non-lethal and not always institutionalized forms of attack (rhetorics).

e. This functional approach allows to provide a general definition of weapon that goes beyond the traditional distinctions of context-based approaches (in example, the difference between external use in conflicts and internal use in law enforcement).

In this way, certain software applications can be considered as weapons, since they concretize such practices and skills in an app (see for instance the DDoS tools available on the internet)..$^{52}$ In this case, the weapon is not the practice itself, but the medium through which it is enacted. We need a notion of "digital weapon" precisely because digital attacks are never immediate, they always require the use of technology in order to happen. At the same time, Simondon's idea of the technical object as the concretization of practices and skills is of extreme utility in order to understand how our technological environment is changing, and how our life is changing along with it.

I will not develop the analysis of this functional model, since this will be the object of another work. In this paper I only wanted to provide a general theoretical framework that could justify the need for a new approach to our understanding of weaponry, and my aim was to point out that the introduction of digital technologies brought some very difficult issues. These issues, of course, are not only theoretical: there are huge ethical and legal problems connected with the offensive potential of digital media. The main difficulty, as I have tried to show, is that the erosion of the usual modern boundaries — war/peace, civilian/soldier, battleground/civic area, combatant/non-combatant — completely disappear. This means that we will have to find new ways to administrate the balance between danger and security, with important implications for individual freedom and privacy.

\footnotetext{
52 Something similar happens when court rule the use of fists as a kind of armed combat. In this case, the hand becomes a weapon because it is used in a certain way, in some cases - those of professional fighters - after a specific kind of training.
} 


\section{Conclusion}

A viable definition of "digital weapon" is necessary because we find ourselves in a technological environment featuring more and more episodes of war and violence. The understanding and the definition of violent acts in our new informational environment is more complex, and it is not always possible to evaluate actions and events based on our traditional notions. Our common sense is still linked to the idea that weapons are a certain kind of objects, that the media of violence are clearly identifiable and well regulated. One of the aims of this analysis was to show that this is no longer the case, and that we cannot rely on our common sense anymore when it comes to determining the relationship between technology and conflict today. This analysis is not just an attempt to clarify some aspects of what I called "hypermodern warfare," even though there are some political issues that need a viable conceptual definition of what a digital weapon is. Much more importantly, this essay aimed at showing that we need new conceptual instruments to face mediated forms of attack in our everyday life. Since information technologies are reshaping every aspect of our life and society, understanding those elements that it is no longer possible to conceptualize with our traditional, pre-digital categories is an absolute priority, and one of the great philosophical challenges of our time.

\section{References}

Alexander C., Jeffrey. "Durkheim's Problem and Differentiation Theory Today." In Social Change and Modernity, edited by Hans Haferkamp and Neil J. Smelser, 179-205. Berkeley: University of California Press, 1992.

Anders, Günther. Die Antiquiertheit des Menschen. Über die Seele im Zeitalter der zweiten industriellen Revolution. München: Beck Verlag, 1961.

Boulding, Kenneth E. "Il est assez typique des esprits très créateurs d'enfoncer de très gros clous mais de taper toujours un peu à côté. " In Pour ou contre McLuhan, ed. Gerald Emanuel Stern, 61-69. Paris: Seuil, 1969.

Bredekamp Horst. Thomas Hobbes. Der Leviathan. Das Urbild des modernen Staates und seine Gegenbilder: 1651-2001. Berlin: Akademie Verlag, 2012.

Casey-Maslen, Stuart. Non-kinetic-energy weapons termed "non-lethal". A preliminary assessment under International Humanitarian Law and International Human Rights Law. Geneva: Geneva Academy of International Humanitarian Law and Human Rights, 2010.

Chamayou, Grégoire. A Theory of the Drone. Translated by Janet Lloyd. New York: The New Press, 2015.

Clausewitz, Carl. On War. Translated by Michael Howard and Peter Paret. Oxford: Oxford University Press, 2007.

Cohen, Julie E. “Cyberspace and/as space.” Columbia Law Review 107 (2007): 210-257.

Department of Defense (DOD). Dictionary of Military and Associated Terms. DOD, 2010.

Eder, Klaus. "Contradictions and Social Evolution: A Theory of the Social Evolution of Modernity." In Social Change and Modernity, edited by Hans Haferkamp and Neil J. Smelser, 320-350. Berkeley: University of California Press, 1992.

Farinelli, Franco. La crisi della ragione cartografica. Torino: Einaudi, 2009.

Floridi, Luciano. The Fourth Revolution. How the Infosphere is reshaping human reality. Oxford: Oxford University Press, 2014.

—. Information: A Very Short Introduction. Oxford: Oxford University Press, 2010.

Forge, John. Designed to kill: The case against weapon research. New York/London: Springer, 2013.

- The morality of weapons research. Why it is wrong to design weapons. New York/London: Springer, 2019. 
Gibson, James Jerome. The ecological approach to visual perception. Boston, MA: Houghton Mifflin, 1979.

Ginzburg, Carlo. Paura reverenza terrore. Cinque saggi di iconografia politica. Milano: Adelphi, 2015.

Gulin, V.P. "A New Conception of War.” Military Thought. A Russian Journal of Military Theory and Strategy 1 (1997): 16-21.

Haferkamp Hans, Smelser J. Neil (eds.). Social Change and Modernity. Berkeley: University of California Press, 1992.

Huyghe, François-Bernard. "Cyberwar and its Borders." In Cyberwar and Information Warfare, ed. Daniel Ventre, 1-30. Hoboken: Wiley, 2011.

Khanna, Parag. Connectography. Mapping the Future of Global Civilisation. New York: Random House, 2016.

Koplow, David A. Non-Lethal Weapons. The Law and Policy of Revolutionary Technologies for the Military and Law Enforcement. Cambridge: Cambridge University Press, 2006.

Latour, Bruno. Pandora's Hope. Essays on the Reality of Science Studies. Cambridge, MA: Harvard University Press, 1999.

Lee, Stephen P. "Weapon of Mass Destruction. Are they morally special?” In War. Essays in Political Philosophy, ed. May Larry. Cambridge: Cambridge University Press, 2008.

Linklater, Andrew. The Transformation of the Political Community. Ethical Foundation of the PostWestphalian Era. Hoboken: Wiley, 2011.

Luhmann, Niklas. "Differentiation of Society." Canadian Journal of Sociology 2, no. 1 (1977): 29-53.

Malley-Morrison, Kathleen, McCarthy, Sherri, Hines, Denise (eds.). International Handbook of War, Torture and Terrorism. New York: Springer, 2013.

McLuhan, Marshall. The Gutenberg Galaxy. Toronto: University of Toronto Press, 2011.

—. Understanding Media. The Extensions of Man. Boston, MA: MIT Press, 1995.

Mitnick, Kevin D., Simon, William L. The Art of Deception. Controlling the Human Element of Security. Hoboken: Wiley, 2003.

Moseley, Alexander. A Philosophy of War. New York: Algora Publishing, 2002.

Normann, Donald A. The Psychology of Everyday Things. New York: Basic Books, 1988.

Rid, Thomas, McBurney, Peter. “Cyber-Weapons.” Rusi Journal 157/1 (2012): 6-13.

Riis, Soren. "The Symmetry between Bruno Latour and Martin Heidegger: The Technique of Turning a Police Officer into a Speed Bump." Social Studies of Science 38, no. 2 (2008): 285-301.

Schmitt, Carl. The Leviathan in the State Theory of Thomas Hobbes. Meaning and Failure of a Political Symbol. Translated by George Schwab and Erna Hilfstein. London: Greenwood Press, 1996.

—. Land and Sea. Translated by Simona Draghici. Washington, DC: Plutarch Press, 1997.

Sferrazza Papa, Ernesto Calogero. Modernità infinita. Saggio sul rapporto tra spazio e potere. MilanoUdine: Mimesis, 2019.

Simondon, Gilbert. Du mode d'existence des objets techniques. Paris: Aubier, 1989.

- Sur la technique (1953-1983). Paris: PUF, 2014.

Sloterdijk, Peter. Im selben Boot. Über die Hyperpolitik. Frankfurt am Main: Suhrkamp Verlag, 1994.

—. Sphären II. Makrosphärologie. Globen. Frankfurt am Main: Suhrkamp Verlag, 1999.

United Nations Institute for Disarmament Research (UNIDIR). Reporting on Conventional Arms Trade (2018). Available at https://unidir.org/sites/default/files/publication/pdfs/repo rting-on-conventional-arms-trade-synthesis-handbook-en-699.pdf. Accessed February $11,2020$.

United Nations. International Instrument to Enable States to Identify and Trace, in a Timely and Reliable Manner, Illicit Small Arms and Light Weapons (ITI). United Nations, 2003.

Vegetti, Matteo. L'invenzione del globo. Spazio, potere, comunicazione nell'epoca dell'aria. Torino: Einaudi, 2017. 
Ventre, Daniel (ed.). Cyberwar and Information Warfare. Hoboken: Wiley, 2011.

- (ed.). Cyber Conflict. Competing National Perspectives. Hoboken: Wiley, 2012. Information Warfare. Hoboken: Wiley, 2016.

Weber, Max. The Vocation Lectures. Science as a Vocation. Politics as a Vocation. Translated by Rodney Livingstone. Cambridge, MA: Hackett Publishing, 2004. 